\title{
ANALISIS BIAYA-VOLUME-LABA SEBAGAI ALAT PERENCANAAN LABA JANGKA PENDEK PADA PERUSAHAAN DAERAH AIR MINUM TIRTA TARUM KAB. KARAWANG
}

\author{
Ade Suhara \\ Amallia \\ Program Studi Teknik Industri, Universitas Buana Perjuangan Karawang \\ Jl. HS. Ronngowaluyo, Teluk Jambe Timur, Karawang \\ Email; ade.suhara@ubpkarawang.ac.id \\ amallia@ptk.ubpkarawang.ac.id
}

\begin{abstract}
:
PDAM Tirta Tarum Kab. Karawang from 2012 to 2014 shows that profits continue to decline, if this continues to be allowed then PDAM Tirta Tarum Kab. Karawang will suffer losses. Therefore the main problem in this study is how sales planning, cost planning and profit planning are expected by applying cost-volume-profit analysis and how the comparison between cost projections made by PDAM Tirta Tarum Kab. Karawang with cost projections resulting from cost-volume-profit analysis.

The data needed is secondary data obtained from PDAM Tirta Tarum Kab. Karawang in the form of data on PDAM profits in 2011 - 2014, total costs in 2011 - 2014, details of elements of 2014 income and projections of company costs according to the project feasibility study made in 1998. The analytical method used is cost separation analysis, least square method trend, break-even analysis, sales forecast analysis, cost projection analysis, 2015 profit planning and comparison of company cost projections with cost projections resulting from profit-volume-profit analysis.
\end{abstract}

\begin{abstract}
ABSTRAK
PDAM Tirta Tarum Kab. Karawang dari tahun 2012 hingga tahun 2014 menujukkan keuntungan yang terus menurun, bila hal ini terus dibiarkan maka PDAM Tirta Tarum Kab. Karawang akan mengalami kerugian. Oleh karena itu permasalahan utama dalam penelitian ini adalah bagaimana perencanaan penjualan, perencanaan biaya dan perencanaan laba yang diharapkan dengan penerapan analisis biaya-volume-laba dan bagaimana perbandingan antara proyeksi biaya yang dilakukan PDAM Tirta Tarum Kab. Karawang dengan proyeksi biaya hasil analisis biaya-volume-laba.

Data yang diperlukan merupakan data sekunder yang diperoleh dari PDAM Tirta Tarum Kab. Karawang berupa data keuntungan PDAM tahun 2011 - 2014, total biaya tahun 2011 2014, perincian elemen-elemen laba rugi tahun 2014 dan proyeksi biaya perusahaan menurut studi kelayakan proyek yang dibuat tahun 1998. Metode analisis yang digunakan adalah analisis pemisahan biaya, metode least square trend, analisis impas, analisis forecast penjualan, analisis cost proyeksi, perencanaan laba tahun 2015 dan perbandingan proyeksi biaya perusahaan dengan proyeksi biaya hasil analisis biaya-volume-laba.
\end{abstract}

\section{Kata Kunci : Least Square Trend, Forecast}

\section{PENDAHULUAN}

Setiap perusahaan memiliki tujuan untuk memperoleh laba maksimum yang kemudian laba tersebut digunakan untuk mengembangkan usaha perusahaan. Laba merupakan tujuan utama yang hendak dicapai oleh perusahaan, laba menjadi sangat penting artinya karena dapat menjamin kontinuitas usaha dan menunjang pertumbuhan perusahaan. Agar 
dapat mencapai tingkat pertumbuhan yang sesuai dengan yang diharapkan maka perlu adanya perencanaan yang matang mengenai strategi pemasaran maupun strategi pengendalian faktor-faktor yang mempengaruhi laba.

\section{TINJAUAN PUSTAKA}

\subsection{Pengertian Biaya}

Menurut Supriyono (2000;16), Biaya adalah harga perolehan yang dikorbankan atau digunakan dalam rangka memperoleh penghasilan atau revenue yang akan dipakai sebagai pengurang penghasilan.

\subsection{Penggolongan Biaya}

Untuk dapat menyajikan informasi biaya yang bermanfaat pada berbagai tingkatan manajemen, akuntansi manajemen harus dapat menggolongkan biaya sesuai dengan informasi yang diperlukan, kebutuhan informasi ini mendorong timbulnya berbagai cara penggolongan biaya.

Menurut Mulyadi (2005:13), Biaya digolongkan sebagai berikut;

1. Menurut Objek Pengeluaran.

2. Menurut Fungsi Pokok Perusahaan

3. Menurut Hubungan Biaya dengan Sesuatu Yang Dibiayai.

4. Menurut Perilaku dalam Kaitannya dengan Perubahan Volume Kegiatan, biaya dibagi menjadi 4, yaitu: biaya tetap, Biaya Variabel, biaya semi variabel.

\subsection{Analisis Biaya Volume Laba}

Mulyadi (1993) mengatakan bahwa analisis biaya-volume-laba merupakan suatu teknik untuk mengetahui pengaruh harga jual, volume penjualan dan biaya terhadap laba perusahaan. Analisis biaya-volume-laba membantu manajemen dalam perencanaan laba jangka pendek.

Analisis biaya-volume-laba yang dapat dimanfaatkan oleh perusahaan. Matz (1988) mengatakan bahwa kegunaan analisis biaya-volume-laba diantaranya adalah sebagai berikut:

1. Membantu pengendalian melalui anggaran

2. Meningkatkan dan menyeimbangkan penjualan

3. Menganalisis dampak perubahan volume penjualan

4. Menganalisis harga jual sebagai dampak perubahan biaya

5. Menganalisis margin kontribus

\subsection{Perubahan yang Mempengaruhi Analisis Biaya-Volume-Laba}

Hubungan antara biaya-volume-laba dipengaruhi oleh beberapa factor atau kombinasi dari faktor-faktor sebagai berikut:

1. Harga Jual Produk

2. Biayan Produksi

3. Volume Penjualan

2.5 Dampak Perubahan Harga Jual Produk, biaya produk, volume penjualan Kenaikan harga jual produk yang diperkirakan menyebabkan terjadinya penurunan

volume penjualan, dapat menurunkan laba bersih perusahaan dan menurunkan impas. Sebaliknya bahwa penurunan harga jual produk yang diperkirakan dapat menyebabkan terjadinya kenaikan volume penjualan akan dapat menaikan laba bersih perusahaan (menaikkan impas).

Sedangkan biaya produk berdampak pada perubahan biaya tetap, perubahan biaya variabel. Dan perubahan volume penjualan secara individual kemungkinan akan berpengaruh terhadap margin kontribusi dan laba bersih. Kenaikan volume penjualan 
menyebabkan margin kontribusi dan laba bersih naik dan penurunan volume penjualan akan menurunkan margin kontribusi dan laba bersih.

\subsection{Model BEP (Break Event Point)}

Mulyadi (1993) mengatakan bahwa impas / BEP merupakan suatu kondisi dimana perusahaan tidak memperoleh laba dan tidak menderita kerugian. Dengan kata lain suatu usaha dikatakan impas jika jumlah pendapatan sama dengan jumlah biaya. Lebih lanjut Mulyadi (1993) mengatakan bahwa ada satu cara untuk mengetahui impas yaitu melalui pendekatan teknik dengan persamaan:

$\operatorname{Impas}($ Unit $)=$

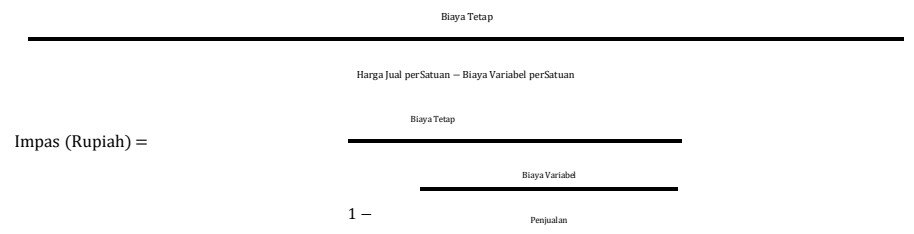

\section{METODELOGI PENELITIAN}

\subsection{Langkah - langkah penelitian}

1. Identifikasi Masalah

Melakukan perencanaan penjualan untuk menghasilkan laba jangka pendek

2. Studi Literatur

Menggunakan jurnal internet dan buku pedukung

3. Studi lapangan

Pencatatan secara langsung dan sistematis serta wawncara

4. Pengumpulan data

- Data primer

- Data sekunder

5. Pengolahan data

Dengan menggunakan Analisis Biaya-Volume-Laba

1. Analisis Pemisahan Biaya

2. Metode Least Square Trend

3. Analisis Impas

4. Analisis Forecast Penjualan

5. Analisis Cost Proyeksi

6. Perencanaan Laba 2015

6. Analisis Pemecahan Masalah

Analisis yang dilakukan setelah dilakukannya pengolahan data adalah: data hasil pengolahan akan dibandingkan antara data yang diperoleh dari lapangan dengan teori yang mendasari yang selanjutnya dievaluasi.

7. Kesimpulan dan Saran

Analisis yang dilakukan setelah dilakukannya pengolahan data adalah: data hasil pengolahan akan dibandingkan antara data yang diperoleh dari lapangan dengan teori yang mendasari yang selanjutnya dievaluasi.

\subsection{Analisis Pemisahan Biaya}

\section{Analisis Pemisah Biaya}

Dalam analisis titik impas, biaya yang dikeluarkan perusahaan harus dipisahkan ke dalam biaya tetap dan biaya variabel. Demikian juga untuk biaya semi variabel yang mempunyai unsur biaya tetap dan biaya variabel harus dipisahkan terlebih dahulu ke dalam kedua jenis biaya tersebut. Menurut Mulyadi (1992) 
alat yang digunakan untuk memisahkan biaya ini adalah analisis trend dengan metode least dengan persamaan garis sebagai berikut :

$$
\begin{array}{ll}
Y & : \text { total biaya } \\
\mathrm{X} & : \text { total produksi } \\
\mathrm{a} & : \text { biaya tetap } \\
\mathrm{b} & : \text { biaya variable } \\
\mathrm{n} & : \text { banyaknya data }
\end{array}
$$

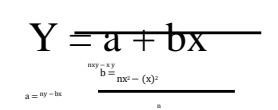

\section{Metode Least Square Trend}

Metode ini digunakan untuk meramalkan jumlah volume penjualan pada tahun 2015. Seperti halnya pada analisis pemisahan biaya maka pemilihan metode least square trend didasarkan pada alasan bahwa metode ini paling sering dipakai dan menunjukkan adanya hubungan garis lurus. Menurut Sudjana (1981) rumus perhitungannya adalah sebagai berikut :

$$
\mathrm{Y}=\mathrm{a}+\mathrm{bx}
$$

dimana :

Y: total penjualan

$\mathrm{X}$ : variabel bebas

$\mathrm{n}$ : banyaknya data

\section{Analisis Impas}

Analisis impas digunakan untuk mengetahui volume penjualan minimum agar suatu usaha tidak menderita kerugian tetapi juga tidak memperoleh laba atau dengan kata lain laba yang diperoleh adalah sama dengan nol.

Menurut Mulyadi (1993) cara untuk menentukan impas adatah:

\section{Analisis Forecast Penjualan}

Analisis forecast penjualan merupakan bagian dari analisis biaya- volume-laba yang dapat digunakan untuk mengetahui perencanaan penjualan tahun 2015 . Menurut Matz (1988) cara untuk menghitung forecast penjualan adalah sebagai berikut :

Sales Tahun 2015 = Ramalan Volume Penjualan Tahun 2015 x Tarif Air per

\section{Meter Kubik}

\section{Analisis Cost Proyeksi}

Analisis cost proyeksi juga merupakan bagian dari analisis biaya- volume-laba yang dapat digunakan untuk mengetahui perencanaan biaya tahun 2015.

Menurut Matz (1988) cara untuk menghitung forecast penjualan adalah sebagai berikut :

Biaya Tetap = Biaya Tetap Tahun Sebelumnya $+(\%$ kenaikan $x$ Biaya Tetap 
Tahun Sebelumnya)

Biaya Variabel = Biaya Variabel Tahun Sebelumnya $+(\%$ kenaikan $x$ Biaya

Variabel Tahun Sebelumnya)

\section{Perencanaan Laba Tahun 2015}

Menurut Matz (1988) perencanaan laba tahun 2015 dapat dihitung dari sales berdasarkan forecast penjualan tahun 2015 dikurangi dengan proyeksi biaya tahun 2015.

Laba Tahun 2015 = Sales Tahun 2015 - Biaya Tahun 2015

\section{PENGUMPULAN DAN PENGOLAHAN DATA \\ 4.1 Pengumpunan Data}

Data yang akan dikumpulkan yaitu :

- Laporan laba rugi tahun 2014

- Perincian elemen- elemen laba rugi tahun 2014

- Perincian volume penjualan dan tarif air tahun 2011 - 2014

- Biaya proyeksi tahun 2015

- Analisis klasifikasi biaya menurut tingkah lakunya

\subsection{Pengolahan Data}

\section{Perhitungan Volume Penjualan Yang Diharapkan}

Volume penjualan yang diharapkan pada masa yang akan datang adalah salah satu faktor penting untuk perencanaan laba. Dalam menganalisis volume penjualan tahun 2015 menggunakan sampel data volume penjualan bulanan selama tiga tahun yaitu mulai dari tahun 2012 sampai dengan tahun 2014 dengan menggunakan Least Square Method. Dari volume penjualan tersebut selanjutnya dapat dilihat besarnya volume penjualan yang diharapkan pada tahun 2015, untuk lebih jelasnya dapat dilihat pada tabel 4.9.

Tabel 4.9. Volume Penjualan Tahun 2014 Peramalan Dengan Metode Least Square Trend

\begin{tabular}{|c|l|c|c|c|}
\hline No & Bulan & X & Y & XY \\
\hline 1 & Jan-12 & 1 & 58.000 & 58.000 \\
\hline 2 & Pebruari 2012 & 2 & 87.000 & 174.000 \\
\hline 3 & Mar-12 & 3 & 57.500 & 172.500 \\
\hline 4 & Apr-12 & 4 & 63.500 & 254.000 \\
\hline 5 & Mei-12 & 5 & 88.000 & 440.000 \\
\hline 6 & Jun-12 & 6 & 65.000 & 390.000 \\
\hline 7 & Jul-12 & 7 & 67.000 & 469.000 \\
\hline 8 & Agust-12 & 8 & 75.000 & 600.000 \\
\hline 9 & Sep-12 & 9 & 62.500 & 562.500 \\
\hline 10 & Okt-12 & 10 & 65.000 & 650.000 \\
\hline 11 & Nop-12 & 11 & 70.000 & 770.000 \\
\hline
\end{tabular}




\begin{tabular}{|r|l|l|c|c|}
\hline 12 & Des-12 & 12 & 75.000 & 900.000 \\
\hline 13 & Jan-13 & 13 & 69.000 & 897.000 \\
\hline 14 & Pebruari 2013 & 14 & 70.000 & 980.000 \\
\hline 15 & Mar-13 & 15 & 65.000 & 975.000 \\
\hline 16 & Apr-13 & 16 & 74.000 & 1.184 .000 \\
\hline 17 & Mei-13 & 17 & 74.500 & 1.266 .500 \\
\hline 18 & Jun-13 & 18 & 68.000 & 1.224 .000 \\
\hline 19 & Jul-13 & 19 & 75.000 & 1.425 .000 \\
\hline 20 & Agust-13 & 20 & 68.000 & 1.360 .000 \\
\hline 21 & Sep-13 & 21 & 60.000 & 1.260 .000 \\
\hline 22 & Okt-13 & 22 & 64.500 & 1.419 .000 \\
\hline 23 & Nop-13 & 23 & 85.000 & 1.955 .000 \\
\hline 24 & Des-13 & 24 & 80.000 & 1.920 .000 \\
\hline 25 & Jan-14 & 25 & 75.000 & 1.875 .000 \\
\hline 26 & Pebruari 2014 & 26 & 84.000 & 2.184 .000 \\
\hline 27 & Mar-14 & 27 & 69.000 & 1.863 .000 \\
\hline 28 & Apr-14 & 28 & 78.000 & 2.184 .000 \\
\hline 29 & Mei-14 & 29 & 79.000 & 2.291 .000 \\
\hline 30 & Jun-14 & 30 & 68.000 & 2.040 .000 \\
\hline 31 & Jul-14 & 31 & 75.000 & 2.325 .000 \\
\hline 32 & Agust-14 & 32 & 85.000 & 2.720 .000 \\
\hline 33 & Sep-14 & Des-14 & 77.000 & 2.541 .000 \\
\hline 34 & Okt-14 & Nop-14 & 78.0000 & 2.992 .000 \\
\hline 35 & 2.450 .000 \\
\hline
\end{tabular}

Y $\quad 2.612 .500$

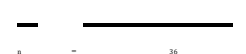

Berdasarkan perhitungan diatas diperoleh nilai a sebesar 72.569 dan b sebesar 112 maka diperoleh persamaan sebagai berikut :

$$
Y=72.569+112 X
$$


Dari persamaan tersebut dapat digunakan untuk menghitung besarnya volume penjualan tahun 2015 sebagai berikut :

Tabel 4.10. Peramalan Volume Penjualan Tahun 2015 Dengan Metode Least Square Trend

\begin{tabular}{|c|l|c|c|c|c|}
\hline No & \multicolumn{1}{|c|}{ Bulan } & X & a & b & Y \\
\hline 1 & Januari 2015 & 37 & 72.569 & 112 & 76.713 \\
\hline 2 & Pebruari 2015 & 38 & 72.569 & 112 & 76.825 \\
\hline 3 & Maret 2015 & 39 & 72.569 & 112 & 76.937 \\
\hline 4 & April 2015 & 40 & 72.569 & 112 & 77.049 \\
\hline 5 & Mei 2015 & 41 & 72.569 & 112 & 77.161 \\
\hline 6 & Juni 2015 & 42 & 72.569 & 112 & 77.273 \\
\hline 7 & Juli 2015 & 43 & 72.569 & 112 & 77.385 \\
\hline 8 & Agustus 2015 & 44 & 72.569 & 112 & 77.497 \\
\hline 9 & September 2015 & 45 & 72.569 & 112 & 77.609 \\
\hline 10 & Oktober 2015 & 46 & 72.569 & 112 & 77.721 \\
\hline 11 & Nopember 2015 & 47 & 72.569 & 112 & 77.833 \\
\hline 12 & Desember 2015 & 48 & 72.569 & 112 & 77.945 \\
\hline & & Total & & 927.948 \\
\hline
\end{tabular}

Dari hasil perhitungan tabel 4.10. diatas menunjukkan bahwa volume penjualan yang diramalkan untuk tahun 2015 adalah sebesar $927.948 \mathrm{M}^{3}$ atau naik sebesar $0,21 \%$ dari tahun 2014.

\section{Perubahan Pola Hubungan Biaya-Volume-Laba}

Setelah dilakukan pemisahan biaya dan perhitungan volume penjualan yang diharapkan maka hasilnya dapat disajikan ke dalam bentuk laporan laba rugi kontribusi. Dari ini akan dapat diketahui sejauh mana pola hubungan biaya-volumelaba serta perubahan faktor-faktor pembentuk laba. Untuk lebih jelasnya dapat dilihat pada tabel 4.11 .

Tabel 4.11. Laporan Laba Rugi Kontribusi Dengan Adanya Perubahan Faktor Pembentuk Laba

\begin{tabular}{|l|r|c|}
\hline \multicolumn{1}{|c|}{ Keterangan } & \multicolumn{2}{c|}{$\mathbf{2 0 1 4}$} \\
\cline { 2 - 3 } & \multicolumn{1}{|c|}{ Jumlah } & \% \\
\hline Penjualan & 3.011 .352 .000 & 100 \\
Biaya Variabel & 558.568 .575 & 18,55 \\
Margin Kontribusi & 2.452 .783 .425 & 81,45 \\
Biaya Tetap & 1.980 .621 .425 & 65,77 \\
Laba Bersih & 472.162 .000 & 15,68 \\
\hline
\end{tabular}


Dari tabel di atas maka dapat diketahui jumlah biaya tetap sebesar Rp.1.980.621.425 atau 65,77\% dari penjualan dan biaya variabel sebesar Rp. 558.568.575 atau 18,55\% dari penjualan. Sedangkan margin kontribusi sebesar Rp. 2.452.783.425 atau $81,45 \%$ dari penjualan dan laba bersih yang dihasilkan sebesar $\mathrm{R}$ p . 472.162.000 atau 15,68\% dari penjualan, oleh karena itu diketahui pola hubungan biaya-volume-laba yang terdiri dari penjualan, biaya variabel, margin kontribusi, biaya tetap dan laba untuk tahun 2014 adalah 1,0000 - 0,1855

- 0,8145 - 0,6577 - 0,1568.

\section{Perencanaan Laba Tahun 2015 Menggunakan Analisis Biaya-Volume-Laba}

Berdasarkan hasil perhitungan analisis impas dapat diketahui bahwa untuk mencapai impas, PDAM Tirta Tarum Kab. Karawang harus dapat menjual air sebanyak 467.117 $\mathrm{M}^{3}$ atau sebesar Rp. 3.888.805.362, sedangkan berdasarkan hasil perhitungan peramalan dengan metode Least Square Trend dapat diketahui ramalan volume penjualan tahun 2015 sebesar $927.948 \mathrm{M}^{3}$. Sedangkan proyeksi penjualan tahun 2015 sebesar Rp. 4.828.299.034, berdasarkan asumsi adanya kenaikan biaya tetap dan biaya variabel yang cukup tinggi tanpa adanya kenaikan tarif air yang relevan dengan kenaikan biaya tersebut maka dapat dipastikan bahwa pada tahun 2015 perusahaan akan menderita rugi. Berikut perhitungannya:

Sales $2015\left(927.948 \mathrm{M}^{3} \mathrm{x} 4.182\right)$

Rp. 3.880.682.670.

Biaya :

$\begin{array}{lll}\text { - } & \text { Biaya Tetap } & \text { Rp. } 3.168 .994 .280 \\ \text { - } & \text { Biaya Variabel } & \text { Rp. } \quad \underline{893.709 .720+}\end{array}$

$$
\frac{\text { Rp. } 4.062 .704 .000-}{\text { Rp. }(182.021 .330)}
$$

\section{ANALISIS DAN \\ PEMBAHASAN 5.1 Analisis}

1. Analisis Perencanaan Laba Tahun 2015 Menggunakan Analisis Biaya-VolumeLaba

Berdasarkan analisis impas dapat diketahui bahwa untuk mencapai impas, PDAM Tirta Tarum Kab. Karawang harus dapat menjual air sebanyak 2.710.044 $\mathrm{M}^{3}$ atau sebesar Rp.4.102.047.831, sedangkan berdasarkan ramalan volume penjualan tahun 2015 sebesar 2.934.006 $\mathrm{M}^{3}$. Sedangkan proyeksi penjualan tahun 2015 sebesar Rp.4.442.085.084, berdasarkan asumsi adanya kenaikan biaya tetap dan biaya variabel yang cukup tinggi tanpa adanya kenaikan tarif air yang relevan dengan kenaikan biaya tersebut maka dapat dipastikan bahwa pada tahun 2015 perusahaan akan menderita rugi. Berikut perhitungannya :

Sales 2015 (927.948 $\mathrm{M}^{3}$ x 5.203)

Rp. 4.828.299.034

Biaya :
a. Biaya Tetap
Rp. 3.168.994.280
b. Biaya Variabel
Rp. $\quad$ 893.709.720+
Rp. 4.062.704.000- 
Perhitungan diatas menunjukkan bahwa dengan tarif sebesar Rp.5.203 per meter kubik maka akan diperoleh penjualan sebesar Rp.4.828.299.034, dengan total biaya sebesar Rp.4.062.704.000 maka diperoleh keuntungan sebesar 
Rp.765.595.034 atau 62,15\% dari penjualan.

Tabel 5 .1. Total Biaya dan Volume Penjualan PDAM (Tahun 2011 - 2015)

\begin{tabular}{|c|c|c|c|c|c|}
\hline \multirow{2}{*}{ Tahun } & \multicolumn{2}{|c|}{ Volume Penjualan } & \multicolumn{2}{|c|}{ Tarif } & $\begin{array}{c}\text { Nilai } \\
\text { Penjualan } \\
\text { (Rp) }\end{array}$ \\
\cline { 2 - 5 } & $\begin{array}{c}\text { Jumlah } \\
(\mathbf{M} 3)\end{array}$ & $\begin{array}{c}\text { Perubahan } \\
(\%)\end{array}$ & $\begin{array}{c}\text { Jumlah } \\
(\mathbf{R p})\end{array}$ & $\begin{array}{c}\text { Perubahan } \\
(\%)\end{array}$ & -1.164 .515 .000 \\
\hline 2011 & 751.300 & - & 1.550 & - & 1.875 .375 .000 \\
\hline 2012 & 833.500 & $10,94 \%$ & 2.250 & $45,16 \%$ & 2.217 .800 .000 \\
\hline 2013 & 853.000 & $2,34 \%$ & 2.600 & $15,56 \%$ & 3.011 .352 .000 \\
\hline 2014 & 926.000 & $8,56 \%$ & 3.252 & $25,08 \%$ & 4.828 .299 .034 \\
\hline 2015 & 927.948 & $0,21 \%$ & 5.203 & $60,00 \%$ & \\
\hline
\end{tabular}

Sumber : Data sekunder yang diolah

\subsection{Pembahasan}

1. Perbandingan Proyeksi Biaya Perusahaan Dengan Proyeksi Biaya Hasil Analisis Biaya-Volume-Laba

Perbandingan proyeksi biaya perusahaan dengan proyeksi biaya hasil analisis biaya-volume-laba adalah untuk mengetahui selisih biaya yang dianggarkan untuk tahun 2015 menurut studi kelayakan proyek yang dibuat tahun 1998 dengan proyeksi hasil analisis biaya-volume-laba. Berikut ini perhitungan selisih proyeksi biaya perusahaan dengan proyeksi biaya hasil analisis biaya-volumelaba untuk tahun 2015.

Proyeksi biaya perusahaan

Proyeksi biaya hasil analisis biaya-volume-laba

Selisih

Berdasarkan perhitungan di atas maka dapat diketahui selisih proyeksi biaya perusahaan untuk 2015 menurut studi kelayakan proyek yang dibuat tahun 1998 dengan hasil analisis biaya-volume-laba adalah sebesar Rp. 1.566.452.300.

\section{KESIMPULAN DAN SARAN}

\subsection{Kesimpulan}

Berdasarkan analisis biaya-volume-laba yang telah dilaksanakan, maka dapat diambil kesimpulan sebagai berikut :

1. Berdasarkan perhitungan perencanaan laba tahun 2015 tanpa adanya kenaikan tarif per $\mathrm{M}^{3}$ ditambah adanya berbagai kenaikan biaya maka dipastikan PDAM Tirta Tarum Kab. Karawang akan mengalami kerugian yang cukup besar yaitu sebesar Rp. 182.021.330. Hal ini dapat diantisipasi dengan meningkatkan tarif air menjadi Rp.5.203 per $\mathrm{M}^{3}$. Jika hal tersebut tidak dilakukan maka diperkirakan untuk tahun-tahun selanjutnya PDAM Tirta Tarum Kab. Karawang akan mengalami kerugian yang cukup tinggi.

2. Berdasarkan perhitungan perbandingan proyeksi biaya perusahaan dengan proyeksi hasil analisis biaya-volume-laba maka diperoleh selisih yang cukup 
tinggi yaitu sebesar Rp. 1.566.452.300, selisih ini disebabkan karena proyeksi biaya perusahaan untuk tahun 2015 dibuat tahun 1998 jadi belum 
dipertimbangkan kondisi perekonomian yang dihadapi Indonesia pada saat ini.

\subsection{Saran}

Setelah memperhatikan kesimpulan-kesimpulan diatas maka beberapa saran yang dapat dijadikan pertimbangan bagi PDAM Tirta Tarum Kab. Karawang adalah sebagai berikut:

1. Dalam melaksanakan perencanaan laba jangka pendek sebaiknya perusahaan menggunakan alat bantu analisis biaya-volume-laba. Analisis ini akan dapat menyajikan berbagai informasi yang bermanfaat untuk menganalisis faktor-faktor yang mempengaruhi pencapaian laba yang diharapkan. Ini diharapkan dapat meningkatkan keuntungan setelah proyeksi yang dilakukan oleh perusahaan terjadi selisih dengan analisis biaya-volume-laba yang dilakukan, ini berarti metode analisis biaya- volume-laba lebih baik dibandingkan dengan metode yang digunakan oleh PDAM Tirta Tarum Kab. Karawang.

2. Tindakan yang harus diambil untuk merencanakan laba tahun 2015 dengan menggunakan analisis biaya-volume-laba adalah :
a. PDAM Tirta Tarum Kab. Karawang sebaiknya menaikkan tarif air menjadi Rp.5.203 per meter kubik agar PDAM Tirta Tarum Kab. Karawang tidak menderita kerugian.
b. PDAM Tirta Tarum Kab. Karawang sebaiknya melakukan efisiensi biaya untuk menimbang kenaikan biaya-biaya pada sektor transmisi dan distribusi
c. Sebaiknya di dokumenkan sesuai dasar tarif yang ditetapkan
d. Tarif yang ditentukan harus sesuai dengan pelayanan kepada konsumen 


\section{DAFTAR PUSTAKA}

Ahyari Agus, “Analisis Pulang Pokok”, Edisi I, BPFE, Yogyakarta, 1986.

Horngen, Charles T. And George Fostor, "Cost Accounting : A Managerial Approach", 6 th Edition, Englewood Clifft, 1987.

Machfoedz, Mas'ud, “Akuntansi Manajemen I”, Edisi Keempat, BPFE, Yogyakarta, 1990.

Mason, D. Robert and Douglas, A., "Teknik Statistik Untuk Bisnis dan Ekonomi”, Edisi ke-9, penerbit Erlangga, Jakarta, 1996.

Matz, Adolf Milton F. Usry and Lawrence Hammer, "Cost Accounting : Planing and Control", $9{ }^{\text {th }}$ Edition, Cincinnati, Ohio : South Western Publising Co., 1998.

Mulyadi, “Akuntansi Biaya”, Edisi Kedua, Yogyakarta : Bagian Penerbit STIE YKPN, 1992.

Suharsimi Arikunto, "Prosedur Penelitian : Suatu Pendekatan Praktek", Edisi Revisi IV Cetakan-II, Renika Cipta, Jakarta, 1998. 